\title{
Comparação de parâmetros periodontais após utilização de contenção ortodôntica com fio trançado e contenção modificada
}

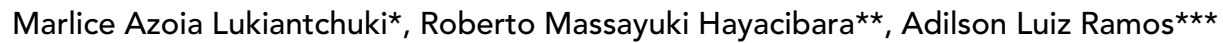

\section{Resumo}

Objetivo: o presente estudo teve como objetivo comparar dois tipos de contenções ortodônticas fixas, em relação a parâmetros periodontais estabelecidos. A contenção com fio trançado é a mais comumente utilizada e a contenção modificada apresenta dobras que têm a finalidade de permitir o livre acesso do fio dental às áreas interproximais. Métodos: para esse estudo cruzado, foram selecionados 12 voluntários que utilizaram, por 6 meses, A) Contenção com fio trançado e B) Contenção modificada - sendo essas fixadas em todos os dentes do segmento anterior. Após esse período experimental, foram feitas as seguintes avaliações: Índice de Placa Dentária, Índice Gengival, Índice de Cálculo Dentário e Índice de Cálculo ao longo do fio de contenção. Os voluntários também responderam a um questionário com relação à utilização, conforto e higienização das contenções. Resultados: foi observado que o índice de placa e o índice gengival foram maiores nas faces linguais $(p<0,05)$ para a contenção modificada. Além disso, o índice de cálculo foi estatisticamente maior $(p<0,05)$ considerando-se as faces linguais e proximais na utilização da contenção modificada. O índice de cálculo ao longo do fio também apresentou valores significativamente maiores $(\mathrm{p}<0,05)$ na contenção modificada. Em relação ao questionário, 58\% dos voluntários consideraram que a contenção modificada é mais desconfortável; e 54\% deles preferiram a contenção com fio trançado. Conclusão: a partir dos resultados obtidos, pode-se concluir que a contenção com fio trançado apresentou melhores resultados do que a contenção modificada, de acordo com os parâmetros periodontais avaliados, além de apresentar maior conforto e preferência na sua utilização.

Palavras-chave: Placa dentária. Inflamação. Cálculos dentários. Contenções ortodônticas.

Como citar este artigo: Lukiantchuki MA, Hayacibara RM, Ramos AL. Comparação de parâmetros periodontais após utilização de contenção ortodôntica com fio trançado e contenção modificada. Dental Press J Orthod. 2011 July-Aug;16(4):44.e1-7.
» Os autores declaram não ter interesses associativos, comerciais, de propriedade ou financeiros, que representem conflito de interesse, nos produtos e companhias descritos nesse artigo.

\footnotetext{
* Especialista em Periodontia pela Associação Odontológica de Ribeirão Preto. Mestre em Clínica Integrada pela Universidade Estadual de Maringá. ** Mestre em Clínica Odontológica pela UNICAMP. Doutorando em Implantodontia pela UNESP.

*** Mestre em Ortodontia pela USP/Bauru. Doutor em Ortodontia pela UNESP.
} 


\section{INTRODUÇÃO}

Contenções fixas na lingual dos dentes anteriores mandibulares são frequentemente usadas para estabilização dos resultados do tratamento ortodôntico ${ }^{3,9,23}$. A indicação para tal contenção é evitar a recidiva e o apinhamento dos incisivos inferiores ${ }^{3}$.

A maior desvantagem no uso de contenções ortodônticas fixas está na tendência ao acúmulo de placa e cálculo ao longo do fio de contenção ${ }^{3,12}$, que, após períodos prolongados, costumam ser a causa da perda de tecidos duros e moles adjacentes ao fio ${ }^{3}$. A presença da contenção fixa dificulta a higiene bucal, uma vez que o fio de contenção gera áreas que são mais difíceis de ser mantidas limpas, favorecendo a formação de placa ao redor dos dentes. Essa situação pode favorecer a formação de cálculos e induzir inflamação gengival e doença periodontal ${ }^{1,23}$.

Convencionalmente, as contenções fixas planas são feitas de fios retilíneos fixados apenas nos caninos $^{25}$, necessitam da cooperação do paciente na sua utilização e exigem substituição quando utilizadas por tempo prolongado ${ }^{7}$. Uma variação dessa contenção, idealizada para facilitar a higiene, apresenta dobras que ficam sob as papilas dos incisivos e caninos, permitindo o livre acesso ao fio dental; porém, é fixada em todos os dentes anteriores inferiores ${ }^{8}$. Essa contenção é conhecida como contenção modificada $a^{7,8,9,17}$.

Num recente trabalho, Shirasu et al. ${ }^{21}$ compararam dois modelos de contenção fixa e mostraram que, nas contenções modificadas, ocorreu maior acúmulo de placa e cálculo - tanto ao longo do fio como na margem gengival - e, consequentemente, maior inflamação gengival. Esse resultado foi atribuído à maior extensão do fio ortodôntico, maior contato com a superfície dentária e pontos de fixação em todos os dentes do segmento anterior. Porém, a contenção avaliada nesse estudo, comparada com a contenção modificada, foi a convencional plana $3 \times 3$, que necessita de união com os dentes apenas nas extremidades, sendo esse um fato relevante para um menor acúmulo de placa e cálculo tanto no fio quanto na margem gengival.

A utilização da contenção com fio trançado colado em todos os dentes do segmento anterior é indicada para os casos de apinhamento severo, assim evitando o risco de recidiva ${ }^{10,26}$. Entretanto, até o momento não existe na literatura nenhum trabalho que compare esses dois tipos de contenção. Dessa maneira, o objetivo desse trabalho é avaliar as condições de acúmulo de placa e cálculo ao longo do fio e na margem gengival e as condições gengivais decorrentes do uso da contenção modificada e da com fio trançado, quando ambas são fixadas em todos os dentes anteriores.

\section{MATERIAL E MÉTODOS}

\section{Seleção dos voluntários}

Foram selecionados doze voluntários para participar desse estudo. Todos foram submetidos a uma anamnese e a um exame clínico bucal. Os critérios de inclusão foram: não estar utilizando aparelho ortodôntico durante a pesquisa, apresentar bom alinhamento nos dentes anteriores inferiores e não apresentar doença periodontal.

Os voluntários receberam um termo de consentimento livre e esclarecido, estando de acordo com as Diretrizes e Normas Regulamentadoras do Conselho Nacional de Saúde (Resolução ${ }^{\circ}$ 196/96) e o estudo foi iniciado após a aprovação pelo Comitê de Ética em Pesquisa com Humanos.

\section{Delineamento experimental}

O estudo foi cruzado, contendo duas fases de tratamento:

a) Utilização da contenção com fio trançado.

b) Utilização da contenção modificada.

O período experimental foi de 6 meses, com 15 dias de intervalo entre as duas fases. Antes de cada fase, os voluntários passaram por raspagem e alisamento radicular dos dentes anteriores inferiores e orientação de higiene bucal. Após o término 
de cada fase, foram realizadas as avaliações clínicas. Todas as avaliações foram realizadas por um único examinador.

\section{Confecção das contenções}

As contenções foram confeccionadas por um único ortodontista, a partir de um modelo de gesso especial obtido de cada voluntário.

\section{Contenção com fio trançado}

A contenção foi confeccionada com fio ortodôntico trançado de espessura 0,020" (Fig. 1) e fixada em todos os dentes anteroinferiores na junção dos terços médio e incisal, prevenindo rotações dos incisivos, alterações na distância intercaninos e não comprometendo a estética $^{16}$. Essa altura foi padronizada através da utilização de um fio dental dobrado ao meio e passado na região interproximal do incisivo central e do lateral de ambos os lados (Fig. 2). Assim, a contenção ficou presa entre as dobras do fio dental e, na face vestibular, foi dado um nó para estabilização da posição, permitindo a manutenção da contenção exatamente no mesmo local do modelo de gesso durante a colagem nos caninos. Essa contenção foi fixada em todos os dentes anteriores.

\section{Contenção modificada}

As contenções modificadas (Fig. 4) foram confeccionadas com fio redondo de $0,6 \mathrm{~mm} / 0,024$ " e fixadas de maneira que as dobras superiores ficassem a $4,5 \mathrm{~mm}$ do ponto mais cervical dos incisivos (Fig. 3), deixando aproximadamente $0,5 \mathrm{~mm}$ de distância da papila lingual ${ }^{14,21}$. Além disso, a porção superior da contenção localizada no centro da face lingual de cada dente foi deixada em contato passivo, para ser usada como ponto de fixação. $\mathrm{O}$ procedimento de colagem foi realizado com o auxílio de um dispositivo de silicona e resina composta Concise (3M, Glendora, CA, EUA) (Fig. 5). $O$ término da resina na região cervical foi mantido em zero grau para que não houvesse área de retenção mecânica para a placa bacteriana ${ }^{7,8}$.

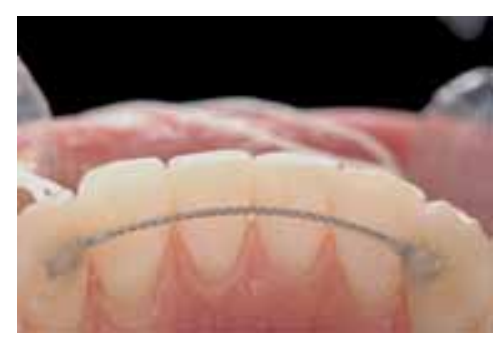

FIGURA 1 - Contenção com fio trançado colada nas extremidades e estabilizada com fio dental.

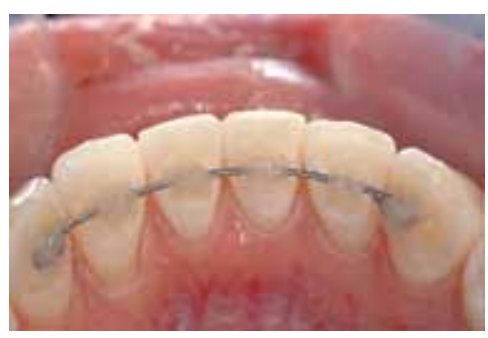

FIGURA 2 - Contenção com fio trançado após fixação aos dentes.

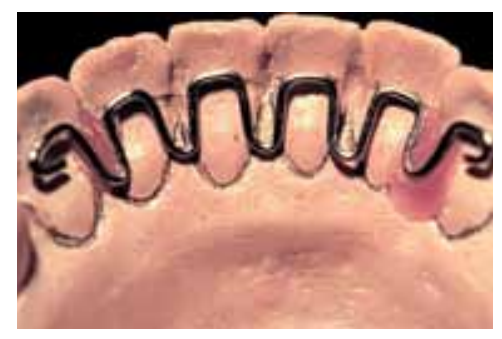

FIGURA 3 - Desenho da contenção modificada, feita com fio $0,024 "$.

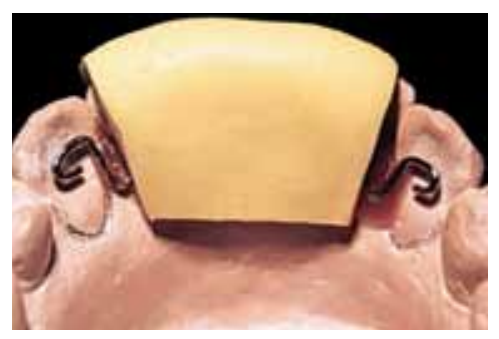

FIGURA 4 - Guia de silicone usado no procedimento de colagem.

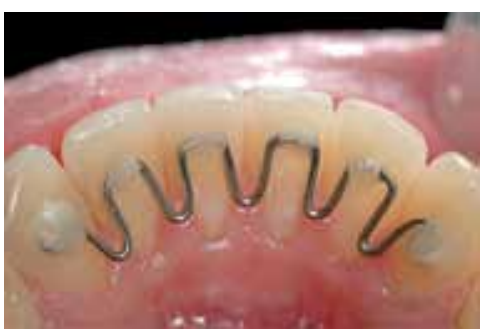

FIGURA 5 - Contenção modificada após fixação aos dentes. 


\section{Avaliações clínicas}

Após cada fase, foram realizadas avaliações periodontais dos dentes inferiores anteriores nas três áreas: duas proximais e lingual, através do Índice de Placa Dental ${ }^{22}$, Índice Gengival ${ }^{18}$ e Índice de Cálculo Dental ${ }^{19}$. Além disso, foi realizada a mensuração do cálculo no fio da contenção ${ }^{3}$. Todos os voluntários responderam a um questionário após a utilização de cada contenção, para a avaliação da aceitação e conforto de ambas as contenções.

\section{Questionários}

Todos os voluntários responderam a um questionário após o término de cada fase do estudo, onde foram analisadas as duas contenções em termos de conforto, facilidade de higienização e aceitação do voluntário.

\section{Análise estatística}

As médias obtidas para as variáveis, índices de placa e gengival, e índices de cálculo, foram comparadas pelo teste de Tukey's Studentized Range (HSD), considerando um nível de significância de 5\%.

\section{RESULTADOS}

Índice de placa

No Gráfico 1 pode-se observar a média dos indices de placa bacteriana para as faces linguais, proximais e totais, quando utilizadas as contenções

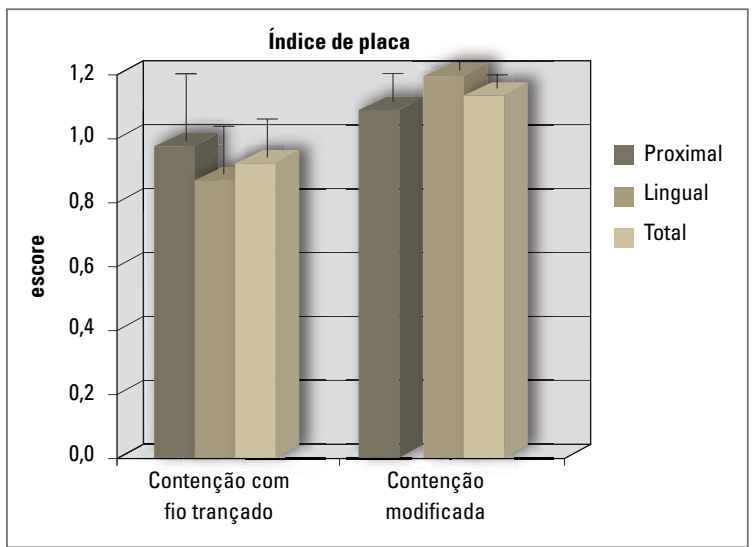

GRÁFICO 1 - Médias e desvios-padrão do índice de placa nas faces proximais, linguais e totais nas contenções com fio trançado e modificadas. com fio trançado e a modificada. Houve maior acúmulo de placa quando utilizada a contenção modificada, sendo os resultados estatisticamente maiores para as faces linguais e totais, quando comparados aos da contenção com fio trançado.

\section{Îndice gengival}

No Gráfico 2 observa-se a média do índice gengival para as faces linguais, proximais e totais, quando utilizada as contenções com fio trançado e a modificada. Os dados foram estatisticamente superiores apenas para as faces linguais, sendo que os maiores índices foram para contenção modificada.

\section{Îndice de cálculo}

As médias dos índices de cálculo dentário podem ser observadas no Gráfico 3. Houve diferença estatisticamente significativa apenas para as faces totais, quando comparadas as contenções com fio trançado e a modificada, sendo maior para a contenção modificada.

\section{Índice de cálculo ao longo do fio}

Os resultados do índice de cálculo ao longo dos fios estão representados no Gráfico 4. Houve maior acúmulo de cálculo ao longo do fio na contenção modificada, sendo essa diferença estatisticamente significativa em relação à contenção com fio trançado.

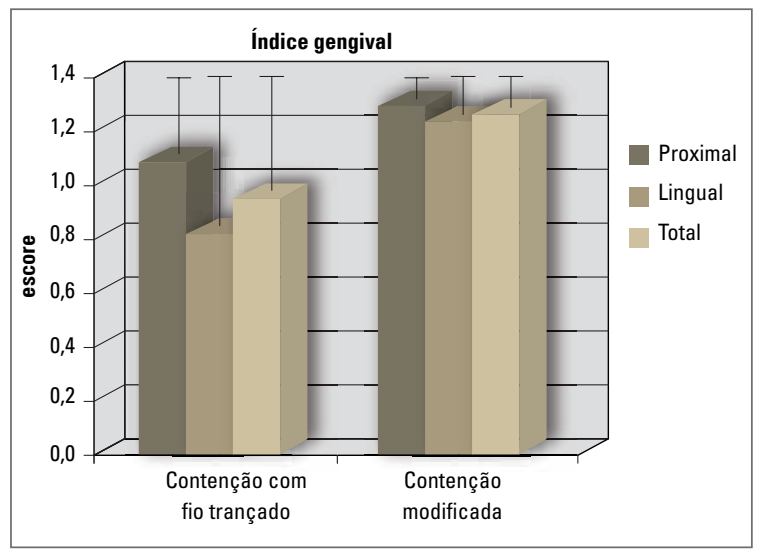

GRÁFICO 2 - Médias e desvios-padrão do índice gengival nas faces proximais, linguais e totais nas contenções com fio trançado e modificadas. 


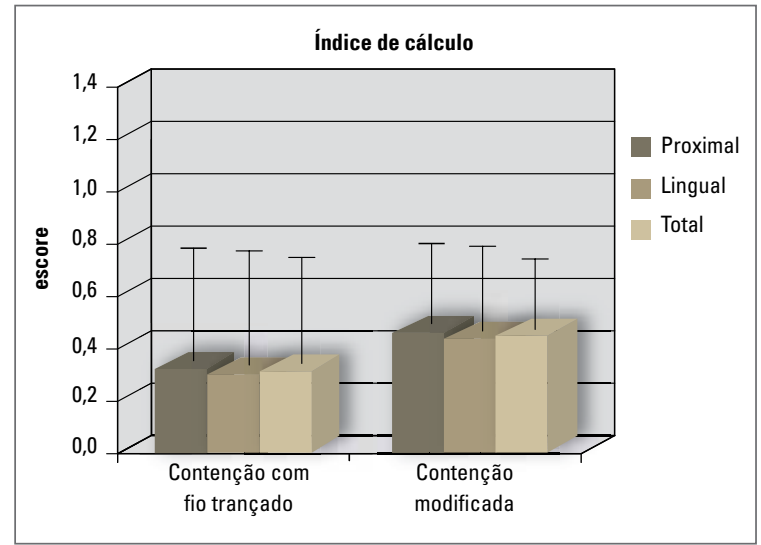

GRÁFICO 3 - Médias e desvios-padrão do índice de cálculo nas faces proximais, linguais e totais nas contenções com fio trançado e modificadas.

\section{Questionário}

Os resultados do questionário estão apresentados na Tabela 1.

Quanto ao conforto das contenções, 58\% dos voluntários acharam a contenção modificada mais desconfortável. Quanto à higienização, 54\% relataram como sendo melhor com a contenção convencional com fio trançado. Quanto à necessidade de utilizar o passador de fio, 79\% afirmaram existir para a contenção convencional com fio trançado, enquanto $21 \%$ apontaram essa necessidade para a contenção modificada. Quanto à preferência, 54\% dos voluntários relataram ser a contenção convencional com fio trançado a melhor contenção, enquanto $46 \%$ preferiram a contenção modificada.

\section{DISCUSSÃO}

As contenções ortodônticas são recursos importantes no tratamento ortodôntico e têm como objetivo a estabilização dos dentes após a movimentação ortodôntica ${ }^{3,23,24}$. Porém, o maior problema da sua utilização está na dificuldade de higienização que o fio de contenção proporciona, gerando um acúmulo de placa e cálculo no fio da contenção e áreas adjacentes ${ }^{3,12}$. Na tentativa de melhorar o acesso às regiões interproximais para utilização do fio dental, as contenções conhecidas como modificadas foram idealizadas ${ }^{7,8,9,17}$.

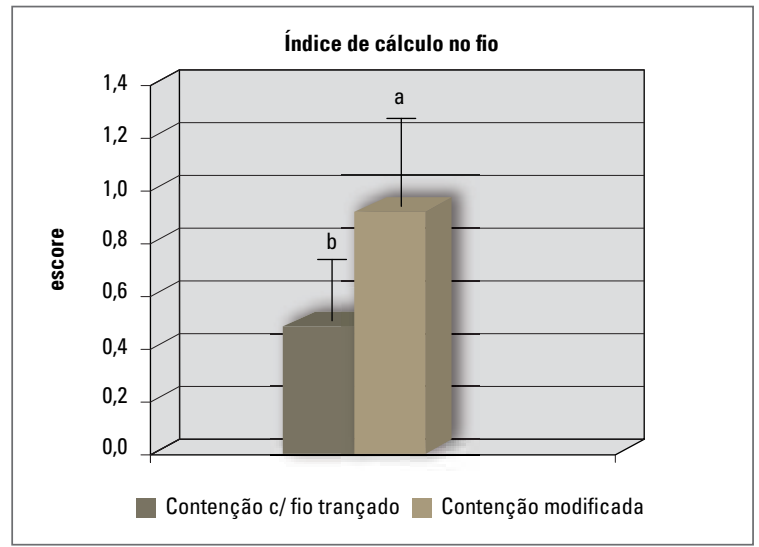

GRÁFICO 4 - Médias e desvios-padrão dos escores obtidos pelo índice de cálculo ao longo do fio das contenções com fio trançado e modificadas.

TABELA 1 - Tabela mostrando o resultado do questionário aplicado aos voluntários.

\begin{tabular}{|ccc|}
\hline $\begin{array}{c}\text { Questionário / } \\
\text { Tipo de contenção }\end{array}$ & $\begin{array}{c}\text { Contenção com } \\
\text { fio trançado }\end{array}$ & $\begin{array}{c}\text { Contenção } \\
\text { modificada }\end{array}$ \\
\hline Conforto na utilização & $58 \%$ & $42 \%$ \\
\hline $\begin{array}{c}\text { Melhor higienização } \\
\text { Necessidade de utilizar o } \\
\text { passador de fio dental }\end{array}$ & $54 \%$ & $46 \%$ \\
\hline $\begin{array}{c}\text { Preferência no tipo } \\
\text { de contenção }\end{array}$ & $79 \%$ & $21 \%$ \\
\hline
\end{tabular}

O presente estudo mostrou que ocorreu um acúmulo maior de placa na contenção modificada, quando comparada à contenção com fio trançado, nas faces linguais e totais (Gráf. 1). Esses resultados corroboram com os encontrados por Shirasu et al. ${ }^{21}$, porém no presente estudo a diferença entre as duas contenções foi quantitativamente menor do que a encontrada naquele estudo. Esse fato pode ser justificado pela contenção com fio trançado, do presente estudo, ser colada nos seis dentes anteriores o que favoreceu o acúmulo de placa nessas regiões. A presença de fios retentivos contínuos cria áreas que dificultam a limpeza ${ }^{4}$. Além disso, a dificuldade na manutenção de higiene traz piores consequências para o periodonto em pacientes que utilizam contenções fixadas em todos os dentes ${ }^{4}$. Já nas faces proximais, não houve 
diferença estatisticamente significativa no acúmulo de placa, mostrando que a contenção modificada, mesmo apresentando livre acesso ao fio dental, não apresentou vantagens com relação ao índice de placa na região proximal, pois em ambas contenções os voluntários conseguiram higienizar de forma semelhante a face interproximal.

Em relação ao índice gengival, esse apresentou-se maior nas faces linguais com a contenção modificada (Gráf. 2), estando de acordo com os resultados encontrados no índice de placa, uma vez que quanto maior a quantidade de placa bacteriana, maior será a inflamação gengival ${ }^{13}$. Isso pode ser explicado pelo desenho da contenção modificada, que possui dobras em forma de "U" na superfície lingual ${ }^{8}$, assim levando a um maior acúmulo de placa e, consequentemente, uma maior inflamação gengival. Já nas superfícies proximais não houve diferença estatisticamente significativa, estando de acordo com os resultados encontrados no índice de placa.

Em relação ao índice de cálculo, esse se mostrou maior na contenção modificada quando comparada à contenção com fio trançado - levando-se em consideração as faces totais, uma vez que as faces proximais e linguais não foram estatisticamente diferentes, embora ambas tenham apresentado maiores médias para a contenção modificada (Gráf. 3). Esse resultado pode ser devido à pequena amostra de voluntários, ao curto período de tempo de avaliação e ao refinamento manual e bom padrão de higiene bucal dos voluntários, por serem acadêmicos de Odontologia.

$\mathrm{Na}$ avaliação do índice de cálculo ao longo do fio das contenções, foi demonstrado que houve maior acúmulo de cálculo para a contenção modificada (Gráf. 4). Isso pode ser atribuído à superfície do fio da contenção modificada ser maior e estar em maior contato com a superfície dentária, estando de acordo com estudos realizados anteriormente ${ }^{21}$.

Quanto ao questionário aplicado a todos os voluntários, 58\% dos voluntários elegeram a contenção modificada como sendo mais desconfortável, reclamando da sensibilidade que essa causava à língua, o que pode estar atribuído ao fato dessa contenção apresentar uma maior extensão do fio ortodôntico $^{21}$. Com relação à limpeza da área interproximal, 79\% afirmaram ser necessário utilizar o passador de fio na contenção com fio trançado; e $21 \%$ afirmaram a necessidade de utilizar o passador de fio na contenção modificada. Desses $21 \%$, todos afirmaram não conseguir passar o fio dental até o sulco gengival. Esse dado pode ser atribuído ao fato de todos os voluntários serem acadêmicos de Odontologia e, portanto, conhecedores da necessidade de passar o fio dental até o sulco gengival. Por isso, 54\% deles afirmaram conseguir melhor higienização utilizando a contenção com fio trançado, uma vez que, mesmo despendendo maior tempo para a higienização, essa se tornava mais completa. Dos voluntários, 54\% afirmaram preferir a contenção com fio trançado, considerando essa melhor do que a contenção modificada pelo fato de conseguirem realizar a limpeza interproximal de forma completa, chegando com o fio dental até o sulco gengival e, também, por acumular menos alimentos durante as refeições.

\section{CONCLUSÃO}

Os resultados demonstraram que a contenção com fio trançado apresentou melhores resultados do que a contenção modificada, de acordo com os parâmetros periodontais avaliados, além de apresentar maior conforto e preferência por sua utilização. 


\title{
Comparison of periodontal parameters after the use of orthodontic multi-stranded wire retainers and modified retainers
}

\begin{abstract}
Objective: To compare two types of fixed orthodontic retainers (a multi-stranded wire retainer and a modified retainer) in relation to established periodontal parameters. The multi-stranded wire retainer is commonly used, and the modified retainer has bends to enable free access of dental floss to interproximal areas. Materials and Methods: For this crossover study, 12 volunteers were selected and used the following retainers for six months: (A) a multi-stranded wire retainer and (B) a modified retainer, both fixed to all anterior lower teeth. After this experimental period, the following evaluations were made: Dental Plaque Index, Gingival Index, Dental Calculus Index and Retainer Wire Calculus Index. The volunteers also responded to a questionnaire about the use, comfort and hygiene of the retainers. Results: The plaque index and the gingival index were higher on the lingual surfaces $(p<0.05)$ for the modified retainer. Furthermore, the calculus index was statistically higher $(p<0.05)$ for the lingual and proximal faces when using the modified retainer. The retainer wire calculus index values were also significantly higher $(p<0.05)$ for the modified retainer. In the questionnaire, $58 \%$ of the volunteers considered the modified retainer to be less comfortable and $54 \%$ of them preferred the multi-stranded wire retainer. Conclusion: The multi-stranded wire retainer showed better results than the modified retainer according to the periodontal parameters evaluated, as well as providing greater comfort and being the retainer preferred by the volunteers.
\end{abstract}

Keywords: Orthodontic retainers. Gingival index. Plaque index. Calculus index.

\section{REFERÊNCIAS}

1. Alstad S, Zachrisson BU. Longitudinal study of periodontal condition associated with orthodontic treatment in adolescents. Am J Orthod. 1979;76(3):277-86.

2. Artun J, Zachrisson BU. Improving the handling properties of a composite resin for bracket bonding. Am J Orthod. 1982;81(4):269-79

3. Artun J. Caries and periodontal reactions associated with long-term use of different types of bonded lingual retainers. Am J Orthod. 1984;86(2):112-8.

4. Artun J, Spadafora AT, Shapiro PA, McNeill RW, Chapko MK. Hygiene status associated with different types of bonded orthodontic canine-to-canine retainers. J Clin Periodontol. 1987;14(2)89-94.

5. Artun J, Spadafora AT, Shapiro PA. A 3-year follow-up study of various types of orthodontic canine-to-canine retainers. Eur J Orthod. 1997:19:501-9.

6. Bearn DR. Bonded orthodontic retainers: a review. Am J Orthod Dentofacial Orthop. 1995;108:207-13

7. Bicalho JS, Bicalho KT. Descrição do método de contenção fixa com livre acesso do fio dental. Rev Dental Press Ortod Ortop Facial. 2001;6(5):97-104.

8. Bicalho JS, Bicalho KT. Descrição do método de contenção fixa com livre acesso do fio dental. Rev Clín Ortod Dental Press. 2002;1(1):9-13.

9. Cerny R. Permanent fixed lingual retention. J Clin Orthod. 2001;35:728-32.

10. Ciruffo P, Nouer D. Contenção pós-tratamento ortodôntico. JBO: J Bras Ortodon Ortop Maxilar. 1997;2:5-11.

11. Dahl H, Zachrisson BU. Long-term experience with directbonded lingual retainers. J Clin Orthod. 1991;25(10):619-30.

12. Gorelick L, Geiger AM, Gwinnett AJ. Incidence of white spot formation after bonding and banding. Am J Orthod. 1982;81(2):92-8.

13. Heier EE, De Smit AA, Wijgaerts IA, Adriaens PA. Periodontal implications of bonded versus removable retainers. Am J Orthod. 1997:112(6):607-16.

14. Janson GR, Dainesi EA, Consolaro A, Woodside DG, de Freitas MR. Nickel hipersensitivity reaction before, during, and after orthodontic therapy. Am J Orthod Dentofacial Orthop. 1998;113(6):655-60.
15. Kaplan $\mathrm{H}$. The logic of modern retention procedures. Am J Orthod Dentofacial Orthop. 1988;93(4):325-40.

16. Knierin RW. Invisible lower cuspid to cuspid retainer. Angle Orthod. 1973:43(2):218-20

17. Lew KKK. Direct-bonded lingual retainer. J Clin Orthod. 1989:23:490-1.

18. Löe H, Silness J. Periodontal disease in pregnancy I. Prevalence and severity. Acta Odontol Scand. 1963;21:533-51.

19. Ramfjord SP. Indices for prevalence and incidence of periodontal disease. J Periodontol. 1959:30:51-99.

20. Riedel RA. An analysis of dentofacial relationships. Am J Orthod. 1957:43(2):103-19.

21. Shirasu BK, Hayacibara RM, Ramos AL. Comparação de parâmetros periodontais após utilização de contenção convencional 3×3 plana e contenção modificada. Rev Dental Press Ortod Ortop Facial. 2007:12(1):41-7.

22. Silness J, Löe H. Periodontal disease in pregnancy. II. Correlation between oral hygiene and periodontal condition. Acta Odontol Scand. 1964;22:112-35.

23. Zachrisson BU. Clinical experience with direct bonded orthodontic retainers. Am J Orthod. 1977;71(4):440-8.

24. Zachrisson BJ. Third-generation mandibular bonded lingual 3-3 retainer. J Clin Orthod. 1995;29(1):39-48.

25. Zachrisson BU. The bonded lingual retainer and multiple spacing of anterior teeth. J Clin Orthod. 1983;17:838-44.

26. Zachrisson BU. Aspectos importantes da estabilidade a longo prazo. Rev Clín Ortod Dental Press. 1997;3(4):90-121.

Enviado em: 27/11/2008 Revisado e aceito: 06/08/2009

Endereço para correspondência

Marlice Azoia Lukiantchuki

Av. São Paulo, 172, sala $1122-11^{\circ}$ andar

CEP: 87.013-040 - Maringá / PR

E-mail: marlice_luk@hotmail.com 